\title{
REVOLUÇÕES PROVINCIANAS NA POESIA DE CABRAL
}

\author{
Éverton Barbosa Correia*
}

Resumo: Tal como havia feito com a figura de frei Caneca e de Natividade Saldanha no mesmo livro A escola das facas (1980), João Cabral de Melo Neto faria algo semelhante com Abreu e Lima neste momento de sua produção em que especulações biográficas e investigação histórica contribuem para sua expressão. Pois, além de o general bolivariano ter atuado na imprensa brasileira de sua época, viu-se envolvido em revoluções ligadas ao passado brasileiro, que vêm a compor explicitamente a obra do poeta a partir de certa altura. Diante disso, interessa analisar como o poeta constitui sua dicção através da exploração da vida dessa personalidade histórica em particular.

Palavras-chave: Poesia brasileira moderna; João Cabral de Melo Neto; história regional do Brasil; subjetividade poética.

\begin{abstract}
Such as João Cabral de Melo Neto had made with the figure of frei Caneca and of Natividade Saldanha in the same book A escola das facas (1980), he would do something similar with Abreu e Lima at this moment of his production in which biographical speculations and historical research contribute to his expression. As well as the Bolivar's general has worked in the Brazilian press, he was involved in revolutions related with the Brazilian past which come to compose the work of the poet explicitly at that time. Before this, it is interested in examining how the poet constitutes his diction properly by exploiting the historical personality life in particular.
\end{abstract}

\footnotetext{
"Universidade Federal da Paraíba.
} 
Keywords: Modern Brazilian poetry; João Cabral de Melo Neto; Brazilian regional history; Poetic subjectivity.

Embora seja uma unanimidade crítica assinalar o livro Museu de tudo como um ponto de inflexão no contexto da obra de João Cabral de Melo Neto, talvez seja no livro seguinte, A escola das facas, onde encontramos as marcas mais evidentes dessa silente mudança em sua produção, quer pensemos em referências ao seu universo familiar ou em referências históricas nas quais o poeta identifica o passado provinciano com que trabalha. De uma maneira ou de outra, podemos ler o manuseio de referências como índice de atualização daquela escritura, que é fiada na história e na geografia que rodeia o autor. Ademais, as referências inscritas na sua obra apontam invariavelmente para a demarcação do universo simbólico que o autor elabora, seja pelas marcas familiares que passam a ser reincidentes naquele livro - a começar pela dedicatória aos irmãos -, seja pelo passado revolucionário de sua cidade natal que, por sua vez, também passam a assinalar um traço da história do Brasil encravado no chão de Pernambuco. Daí parecer curioso que um escritor tão infenso a especulações biográficas, inesperadamente, desate a descrever a vida de personalidades históricas no livro A escola das facas, tais como a de frei Caneca, Natividade Saldanha, Antonio de Moraes Silva e Abreu e Lima - todos convertidos em título e matéria de poemas. Diante disso, podemos enxergar o cruzamento das esferas pessoal e histórica, que, apesar de nem sempre serem compatíveis, adquirem tonalidade singular na escrita cabralina, já que subjetividade e representação social fogem do lugar comum na sua expressão. Por isso, a descrição da vida de personalidades pernambucanas, ali grafadas, projeta novas imagens na história brasileira, que interferem no espaço simbólico, deixando-o mais arejado, inclusive porque permite outra percepção da emancipação nacional, nem tão idealizada nem tão centralizada como é a que se desencadeia dos cômodos da corte, instalada no Rio de Janeiro oitocentista. Em vez disso, com outro escopo, podemos olhar de 
viés e visualizar alguns entraves que nortearam a caracterização do Brasil como um espaço nacional, sob a mediação da dinastia bragantina. Para tanto, basta acompanharmos o delineamento de figuras que não se incrustaram na vida cortesã fluminense e que se esfumaram na historiografia nacional, para que possamos enxergar de outro modo o que nos fez ser brasileiros no devir que se fez histórico para nós, tal como o que foi traçado no poema que se segue.

\author{
Abreu e Lima \\ Ao capitão Abreu e Lima \\ concederam a estranha honra: \\ ele foi convidado a ver \\ fuzilar o pai, Padre Roma. \\ O capitão Abreu e Lima \\ ante a distinção concedida \\ se foi de quem a concedeu: \\ o rei e o vice da Bahia.
}

Se foi para a Venezuela

vestir a farda de Bolívar:

não era a sua, mas pregava

uma independência com a vida. (MELO NETO, 2008, p. 414)

Como está gravado no poema, o pai de Abreu e Lima foi fuzilado em decorrência de ter sido revolucionário ativo na Revolução pernambucana de 1817 , quando o filho acabara de receber a patente de capitão de artilharia pela Academia Real Militar, sediada no Rio de Janeiro. De volta a Pernambuco, o capitão se viu envolvido em episódio que lhe resultou inglório. Pouco antes da irrupção revolucionária, Abreu e Lima recebera ordem de prisão do Ouvidor de Olinda, Antonio Carlos Ribeiro de Andrada Carvalho e Silva, que viria encabeçar o levante e compor seu Conselho. Transferido para a Bahia para cumprir pena, o 
capitão Abreu e Lima seria detido na fortaleza de São Pedro no mesmo mês em que seu pai para lá se dirigira com o propósito de expandir o movimento revolucionário. Por coincidência, ficaria encerrado no mesmo cárcere em que seu filho já estava confinado e, depois dele, todos os demais revolucionários presos, inclusive o próprio Antonio Carlos. A tal episódio se deveu o argumento utilizado pelo Padre Roma de que teria ido parar ali para interceder pelo seu filho, quando instado pelo júri composto ilegalmente pelo Conde dos Arcos (o vice-rei mencionado no poema) para deliberar sobre seu fuzilamento. Na verdade, sua captura tinha se devido a características de seu barco - cuja vela se distinguia das usadas naquela localidade -, bem como aos movimentos suspeitos ao longo da costa baiana, que logo despertaram a curiosidade das milícias já postas de prontidão pelo Conde dos Arcos (PAGANO, 1938, p. 130). Detido e trazido a terra, de imediato a identidade do padre foi reconhecida dentre aqueles que, aos rasgos, se pronunciaram contra o império, antes mesmo de sua consolidação em terras brasileiras.

quando chegou a Pernambuco a notícia da vinda da família real portuguesa ao Brasil, o padre Abreu e Lima convoca seus amigos e lhes propõe que se não recebesse o príncipe regente D. João, sem que ele se prestasse a outorgar uma constituição política; porém essa idéia de grande alcance e importância não foi aceita [...] e quer pelas suas qualidades pessoais, quer pelos seus talentos e ilustração, foi ele um dos patriotas que mais se distinguiram na propagação da idéia e nos meios da sua realização. (COSTA, 1981, p. 574)

O vulgo padre Roma também vestiu o hábito da Ordem de Cristo - privilégio concedido a poucos brasileiros -, embora não possuísse outros títulos honoríficos, tal como se verifica no rosário nobiliárquico que se desprende dos seus ramos familiares. Este título seria, já de si, um indício de que também era bem nascido entre as distintas famílias pernambucanas: sendo filho 
do capitão Francisco Ignácio Ribeiro de Abreu e Lima e neto do coronel Lourenço Gomes de Abreu e Lima, podia oferecer aos seus filhos o direito de servir na Academia Real Militar, oportunidade só concedida a nobres ou oficiais de alta patente, o que sua família tinha a contento. Também aí, percebe-se que Abreu e Lima realiza aquele protótipo de revolucionário, cujas ligações com a nobreza de ascendência portuguesa já aclimatada ao Brasil se fazem evidentes. José Ignácio Ribeiro de Abreu e Lima (padre Roma) se ordenou frade carmelita no convento de Goiana, em 1784, respondendo pelo nome de frei José de Santa Rosa, mas seu percurso não se restringiu ao âmbito religioso. Ao contrário, sempre foi pautado por uma atuação política que se consumou com o episódio de 1817, quando foi encarregado de expandir o movimento revolucionário à Bahia, onde foi preso e executado.

No dia 28 de Março, a pedido do infeliz patriota, Abreu e Lima saiu da fortaleza para a cadeia, e aí, banhado em lágrimas, abraçou seu idolatrado pai, que no dia seguinte foi arcabuzado no campo de Sant'Anna; e para maior ostentação dessa cena tristíssima, obrigaram ao jovem Abreu e Lima a assistir a lúgubre festa da tirania, a execução do seu pai.

'Fácil é de compreender-se como uma mão de ferro arrancava o coração traspassado de vivíssima dor de Abreu e Lima, na sua própria frase, quando ele, debulhado em copioso pranto, foi arrancado para sempre dos braços de seu querido pai para dar-se começo ao sacrifício desse mártir da liberdade, dessa vítima do puro entusiasmo pela emancipação política da pátria. [...] Depois desse horrível transe, Abreu e Lima ainda passou alguns meses na cadeia, em companhia de um seu irmão e de outros patriotas que eram remetidos presos de Pernambuco. Em outubro de 1817, conseguiu ser solto com seu irmão, e obtendo da Maçonaria o auxílio de uns 100 pesos em moeda, abandonaram a pátria e embarcaram-se para os Estados-Unidos, onde chegaram em fevereiro de 1818. (COSTA, 1981, p. 550) 
A considerar a ênfase no episódio e o próprio talhe que é dado a Abreu e Lima, provavelmente, foi essa a fonte de que João Cabral se valeu para compor o seu poema, cujo recorte temporal se estende daí a mais um pouco, bem menos curto do que a vida de Abreu e Lima que prosseguiu insone ainda vários anos, atormentado pela morte do pai. Quase um ano depois de fuzilado o pai, em fevereiro de 1818, Abreu e Lima junto a seu irmão Luís Ignácio Ribeiro Roma - que havia sido detido e humilhado diante do pai, quando de sua prisão na Bahia - desembarcariam nos Estados Unidos. De lá rumaram para Porto Rico, depois de Abreu e Lima se desavir com Antonio Gonçalves Cruz Cabugá, enviado no ano anterior pela comissão revolucionária em busca de ajuda norte-americana, que não logrou nada. Então, fixaram-se os dois irmãos na Venezuela, ficando um como comerciante que logo prosperou e o outro se alistando no exército revolucionário de Simon Bolívar. Com o êxito comercial alcançado, Luís Ignácio voltou ao Recife, onde fundou o Diário novo, que viria a ser o principal libelo a favor da Revolução pernambucana desencadeada em 1848 e que estava situado exatamente na Rua da Praia. Como nesta rua se reuniam também muitos comerciantes estrangeiros, notadamente portugueses, então, chamados pejorativamente de "marinheiros", logo se fixou a pecha de "praieiros" a quem se opusesse ao governo, fosse por ser jornalista ou por ser português, ainda que uma das principais reivindicações dos ditos praieiros fosse a nacionalização do comércio a varejo, e não a partilha com os estrangeiros.

Abreu e Lima só voltaria ao Brasil em 1832, depois de passar pela Corte de Luís Felipe, em 1831, no auge de seu prestígio, onde travou contato com D. Pedro I, com quem logo se identificou. A esse episódio se deveu sua adesão ao partido Caramuru, pró-absolutista, que reclamava a volta do imperador. Para quem teve pai revolucionário em 1817 e se alistou no exército bolivariano, uma atitude dessas pode parecer contraditória. Mas a contradição já se desfaz se pensarmos que ainda eram muito 
recentes suas desilusões com o exército revolucionário, que se convertera em mais um palanque do caudilhismo. A partir disso, o brado revolucionário com vistas ao fortalecimento do feudo doméstico se fazia um artifício retórico já conhecido por Abreu e Lima. E para um militar que havia convivido com grandes homens, inclusive com o próprio Bolívar (CHACON, 1983), a falta de reconhecimento do mérito lhe soava ainda mais desprezível do que qualquer outro pecado capital. O seu idealismo romântico se via completamente desagregado quando aterrado no Brasil, de onde não faltavam maus exemplos de lisura e correção. De temperamento sanguíneo, a Grã-Colombia sonhada também não podia lhe servir de pátria, tendo ficado no poder dos líderes pseudorrevolucionários com quem se indispusera em nome da causa do seu muito estimado general Bolívar.

Volta ao Recife em 1844, depois de 27 anos de ausência, com significativa passagem pelo Rio de Janeiro, onde polemizara com figuras do porte de um Varnhagen e de um Feijó, inclusive com interesse literário, o que já rendeu alguns estudos (SOUZA, 2007, p. 41-53). Assim como Abreu e Lima, seu irmão Luís Ignácio havia se tornado revolucionário compulsivo, tendo se envolvido na Revolta dos Afogados de 1829 e na revolta capitaneada pelos irmãos Carneiro, de 1834. Agora seu Diário novo se tornaria um dos eixos mais efetivos da Revolução pernambucana, que se estendera de 1848 a 1849. Também é digno de nota que seu outro irmão, João Ignácio Ribeiro Roma, tendo participado da Confederação do Equador em 1824, tenha sido alvejado com um tiro na cabeça, por ocasião da retirada das tropas praieiras que invadiram o Recife pelo norte (CARNEIRO, 1960, p. 130). Dentre os muitos epítetos conferidos aos revolucionários que se reuniam em torno da Rua da Praia, um deles era "os filhos do padre Roma".

Sob tal perspectiva, o perfil de Abreu e Lima se nos afigura um espectro exemplar. Não por encarnar, naquele momento, o protótipo de revolucionário àquele incendiário ano de 1848, e sim porque ilustra, nos devidos termos, o quinhão de contradições 
em que a Revolta Praieira estava envolvida e, por extensão, a sua persona também. Sendo filho de uma família tradicional, mesmo porque o seu pai combatera ao lado do barão da Boa Vista até 1817, estava imbuído de todo o arsenal de idéias francesas pósrevolucionárias, mas sem vínculo nenhum com o poder vigente, apesar de ter assumido a condição de porta-voz dos demais proprietários de engenhos desconsiderados pela política cavalcanti (LIMA SOBRINHO, 1949, p. 30). Além desses, havia também uma massa esfarrapada, os chamados molambos, que pareciam conferir algum sentido ao que saía das palavras do general, até porque estavam desprovidos de outras possibilidades que não as decorrentes da política baronista, tal como os senhores-deengenho que lhes serviam de esteio. Diante disso, o perfil do "general das massas" se iluminava em perspectiva, devido ao passado revolucionário do pai e também à sua investidura junto ao exército de Bolívar.

Será esse mesmo ponto de sua figura que João Cabral vai eleger como elemento de apreciação, só que a exploração do poeta para aí. Já o próprio Abreu e Lima se firma em Pernambuco para adotar a postura de teórico e propagandista do movimento praieiro, o que lhe custou um processo, onde também era tratado por General - julgado por Nabuco de Araújo, já nos idos de 1850 (MELLO, 1979, p. 452-464). O mais estranho do poema é que os episódios referidos pelo poeta não esgotam o repertório da personagem, que se desdobra em eventos posteriores ao tempo recortado no poema. Com isso, o seu enredo vai a contrapelo, inclusive, da vida do "general das massas", que é distorcida na medida em que é mostrada apenas em parte.

Durante a Revolução praieira, Abreu e Lima não se empenhou no campo de batalha e a verdade é que manteve previdente distância dos levantes armados, embora a Rua da Praia continuasse a servir como pólo aglutinador da revolução, não só no plano simbólico, mas também na participação dos filhos de padre Roma naquele evento. Aliás, desde Um estadista do império 
(NABUCO, 1997, p. 93-120), muito intérprete daquela revolução já reiterou que a Rua da Praia foi mais levada pelo movimento do que conseguiu orientá-lo. E a esse respeito, é preciso frisar que a posição de Abreu e Lima não ajuda a refutar o argumento, figurando mais como personagem estratégica do que militante engajado. Talvez a isso se deva o papel simbólico que ele acabou tomando, após o fracasso revolucionário.

A imprecisão do perfil que se descola da historiografia que o rodeia é similar à imagem que João Cabral timbra no seu poema. Por isso, todos os comentários desenvolvidos até agora visaram não só a exploração do que o poema mostra ou suas entrelinhas revelam, mas, sobretudo, a explicitação do que o poema deliberadamente se exime de explorar e que passa pela participação do general de Bolívar na Revolução Praieira. Daí pode-se inferir algo acerca da intenção do autor, que talha Abreu e Lima como capitão, e em função da Revolução de 1817 - a qual só vivenciou lateralmente -, e em campanha de Bolívar, mas sem relacioná-lo aos acontecimentos posteriores, entre os quais se destaca sua participação mais efetiva no solo pernambucano, nos anos de 1848 e 1849.

Cumpre que se pergunte, pois, o porquê da insistência de João Cabral na patente de capitão, quando o próprio Abreu e Lima se intitulava general nos seus panfletos e assim era reconhecido, inclusive no julgamento a que foi submetido em decorrência da Praieira. Talvez se devesse ao fato de ele querer registrar em poesia, de outro modo, o episódio específico de 1817, que passa pela prisão do capitão e pelo fuzilamento de seu pai, até sua adesão ao exército de Bolívar. Se for assim, a considerar a precisão histórica de sua obra, tal episódio se faz curioso no contexto em que surge, uma vez que Abreu e Lima, antes de ir à Bahia, como atesta o poema, fora ao Rio de Janeiro, onde havia recebido a patente de capitão, inclusive. Além disso, após se ir a Bolívar, só voltou ao Recife depois de muito passear, da Europa ao Rio de Janeiro, onde teve sua patente de general reconhecida no Brasil, tendo lhe sido 
conferida inicialmente em Bogotá. Tudo isso aponta para o perfil da personagem do poema, que, mais do que um sujeito urbano do Recife, caracteriza-se como um cosmopolita, desde antes da morte de seu pai e assim continuou depois do fracasso da Grã-Colombia, que é o tempo recortado no poema. Tal como aparece no poema, o perfil de Abreu e Lima demanda uma compreensão temporal contígua ao da celebração de um mito, anterior ao tempo de sua participação no exército bolivariano, depois da qual a imagem do nosso general se esfuma.

A partir de certa altura de sua produção - onde podemos localizar o A escola das facas e, por extensão, o poema "Abreu e Lima" -, a forma utilizada pelo poeta se aproxima de algo como que de um cacoete de expressão, mesmo sem abrir mão do rigor que lhe é constitutivo. A considerar quem buscou renovações toda uma vida, a partir de certa altura renovar-se coincide com repetir-se no plano formal e retomar-se no plano histórico. Do poema podemos destacar, ainda, os substantivos nucleares, que, na sequência, se dispõem assim: honra, distinção, farda, independência e vida - o que é demasiado estranho, sendo o poeta avesso a substantivos abstratos. Além desses, destacam-se ainda os substantivos próprios, a saber, Abreu e Lima, Padre Roma, Bahia, Venezuela e Bolívar. Como desdobramentos desses, podemos considerar alguns qualificativos, que servem para designar os sujeitos envolvidos naquela história, a exemplo "capitão", "rei" e "vice", além do já mencionado "padre". Estranho mesmo é que, em meio a tantos nomes, não apareça um José Inácio, um Simon... Quero dizer, todos os nomes constantes no poema, sejam qualificativos ou não, apontam para uma cristalização da linguagem, identificada, sobretudo, nas honrarias, títulos e sobrenomes. A ponto de que os sujeitos ali apresentados parecem se configurar mais pelo que representam do que por aquilo que foram ou viveram de fato, como se não interessasse a pessoa que cada um foi.

Essa mesma redução pode ser evidenciada de outra maneira, se nos restringirmos a outro plano do vocabulário, 
quando dispomos das seguintes formas verbais nas duas primeiras estrofes: conceder e convidar. Os verbos apontam para o discurso protocolar e oficioso, que caracterizam sobremaneira os universos militar e diplomático. Isso, de certa forma, é contradito nos verbos da última estrofe, que criam uma desestabilização entre si, como se vê pela oposição entre "vestir" e "pregar". Os dois verbos, assim postos, parecem resumir a determinação militar e a ascese religiosa, que, entrelaçados, dão a dimensão do contexto do poema e até do perfil de Abreu e Lima, que oscila de uma esfera a outra. Sobretudo porque se refere a um pregar com a vida, tal como aconteceu com aquele que vestiu a farda de Bolívar e por ela lutou como se fosse a própria pele, já que, debaixo daquelas vestes, quase morreu, assim como o pai morrera por outra causa e sob outra indumentária. Os vínculos que os unem, decerto podem se estender da vida para o verbo, que se apresenta de início na passiva até que aparece o sintomático "se foi". No primeiro momento, "se foi de quem" e no segundo, "se foi para", o que dá bem a dimensão de um alguém de quem se vai e um lugar para onde se vai. Assim, faz surgir certo perfil de Abreu e Lima no momento em que se aproxima de Bolívar, quando revela os princípios de que estava imbuído o capitão.

O fuzilamento do pai se torna ato fundador também no poema, uma vez que tudo quanto o capitão fizera parece ser decorrente daquele acontecimento primeiro e marcante, soprando-lhe um espírito que demanda celebração da sua memória, com sangue. Talvez agora devamos retomar os fios daquele raciocínio em que história e simbolização se atam para constituir a expressão de João Cabral de Melo Neto, sem esquecer que a dimensão histórica se alimenta de um poder simbólico, que fica ainda mais fortalecido quando entranhado numa matriz formal tão vigorosa como é a que está sendo acionada. Assim como a história narrada por João Cabral carrega consigo a reivindicação de se instituir em oposição a um discurso já existente, de igual modo a matriz formal forjada por ele se opõe a certa tradição. 
Assim colocado, o problema nos dá a dimensão de um sujeito circunstanciado e consciente dos modelos históricos e formais com que tem de lidar. Fundidas as dimensões formal e histórica, no que cada uma tem de particular, chegamos a um sujeito "cabral", objetivado nos versos de um certo João, que insiste em se opor, de uma maneira singular, ao que está posto, seja como matéria ou como poesia. Reforçaria, ainda, que o reajustamento do discurso histórico saído da boca de João Cabral opõe-se a ambas as matrizes brasileiras, seja do Instituto Histórico Geográfico Brasileiro, seja ainda do Instituto Arqueológico Histórico Geográfico Pernambucano (SCHWARCZ, 1993, p. 99140). Mesmo tendo ocasionalmente sido inspirado por escritos de membros daquele instituto pernambucano, como é o caso de Mário Melo - que prefigurou o Auto do frade -, não significa dizer que o poeta esteja de todo integrado à produção dali oriunda.

O fato de se colocar como uma voz dissonante no contexto da literatura brasileira não se deve exclusivamente à excentricidade do autor, e sim ao modo como uma sensibilidade divergente se fia pelo restabelecimento de certo discurso histórico, que o poeta não cansa de emendar. Por conta disso, não é de todo seguro fazer uma acomodatícia separação entre sujeito poético e história regional, uma vez que esses termos são confluentes na poesia de João Cabral de Melo Neto, desestabilizando a ambos, o sujeito e a história. Aliás, se tivermos de tecer considerações sobre um, inapelavelmente resvalaremos em iluminações sobre o outro. O sujeito, porque não é necessariamente através de um "eu" que o reconhecemos na obra de João Cabral, mas antes de tudo pela matéria abordada na qual o autor se projeta, através de um modelo formal próprio que se converte em veio expressivo; a história, porquanto se vê algo de renovação no seu discurso, que demanda novos sujeitos para sua leitura, sendo a figura de João Cabral portadora de voz privilegiada, que contradiz a convenção instituída. 
Dos livros de João Cabral, o A escola das facas é um dos que reúne maior quantidade de referências à história que se desenrola a partir de Pernambuco, apontando para a memória que o autor reclama. É bem sabido também que toda a parte de sua produção que remonta ao Recife foi feita quando ele estava distante da cidade e, por conseguinte, todo seu discurso sobre Pernambuco ganha automaticamente o estatuto de reminiscência, cuja necessidade de rememoração se faz imperativa. Ao ter elegido uma figura tão controversa quanto Abreu e Lima para compor sua obra, é necessário perguntar qual a reivindicação que o autor está fazendo para sua produção artística, sendo ele um poeta e o outro, um militar. Em última análise, cabe a pergunta de qual subjetividade está sendo acionada, uma vez que ela não está infensa à matéria com que trabalha, sobretudo porque estamos falando numa subjetividade poética, que, mais do que absorver tudo quanto possa se afigurar como seu exterior, se inscreve no próprio objeto manipulado (SECCHIN, 1999, p. 315). Também a isso se deve considerável dificuldade de identificar o sujeito cabral, devido ao fato de sua poesia produzir um efeito contrário ao que se espera da linguagem poética. Linguagem essa que também se estrutura por meio de uma subjetividade, cuja expressão não é espontânea para o autor e se faz através de índices históricos com os quais identificamos algo da vida e das eleições do poeta. $O$ interesse em precisar o grau de aproximação entre o poeta diplomata e o general revolucionário reside, pois, no fato de que aqui estamos lidando com uma personalidade histórica que é a um só tempo política e literária, se entendermos como literatura a produção jornalística, historiográfica e sociológica feita por Abreu e Lima.

Assim, estabelece-se uma relação viva e dinâmica entre a representação histórica associada à personagem e o tipo de elaboração poética que o autor aciona. A história presente na obra de João Cabral só aparece com nitidez, porque inscrita num lastro simbólico, que orienta o enredo de sua narração e se oferece 
como esteio capaz de avivar a compreensão da história do Brasil. Para tanto, a descrição de uma vida parece funcionar melhor a seus propósitos, porque torna mais palpável a história retomada e se inscreve num dos símbolos pernambucanos, já convertido em nome de praça, refinaria e cidade. Ademais, a apresentação poética de Abreu e Lima não se restringe à sua celebração, mas apresenta certo conjunto dos conflitos pelos quais passou, o que só acende o traço do tempo e de uma experiência, mais do que o de uma insígnia.

Como se vê no poema, convidar filho de padre para assistir ao fuzilamento do pai não era dos acontecimentos mais corriqueiros, ainda mais sob a crença popular de que matar padre dá azar. Tampouco era comum ser alistado no exército de Bolívar numa época em que nem mesmo a idéia de nacionalidade estava consolidada entre nós. Além disso, poderíamos ressaltar as campanhas e polêmicas em que Abreu e Lima esteve envolvido no Brasil, que vão desde a reivindicação pelo reconhecimento de sua patente de general, passando pela Revolução Praieira, até as polêmicas que desenvolveu - fosse pelo socialismo ou pelo maior reconhecimento do espaço feminino.

Dos filhos de padre Roma, Abreu e Lima foi o que mais durou e com uma vida fulgurante, quase reluzente: após sua estada no Rio de Janeiro, retornou ao Recife e passou a colaborar na imprensa e a polemizar contra os bacharéis da Faculdade de Direito, já que seu título de bacharel, adquirido quando de sua formação militar naquela cidade, implicava formação superior, tendo ele atingido a patente de capitão aos 22 anos. Passadas as escaramuças junto ao exército de Simon Bolívar, sua interferência passou a ser mais de feição intelectual do que militar. Como havia mantido contato com grandes nomes da política internacional, ficou a par das grandes teorias sociais da época, a ponto de ter sido pioneiro no Brasil com a visão da história como luta de classes (CHACON, 1965, p. 145-190). A luta em campo de batalha se estendia agora a outras frentes, com a mesma paixão revolucionária de antes, o que no poema está sugerido através dos 
versos: "Não era a sua, mas pregava/ uma independência com a vida." A sentença, que poderia soar retórica, ganha outra dimensão no interior do poema, pelo perigo de vida a que Abreu e Lima se expusera reiteradas vezes, desde a morte do pai: pelo risco de retaliação imperial, pelo alistamento no exército bolivariano onde liderou batalhas importantes - e, cessadas as lutas ao longo da América Latina, envolvera-se noutras causas libertárias, cujo maior exemplo é o da Revolução Praieira.

No poema em foco, o tratamento formal se aproxima mais do estilo sedimentado pelo autor ao longo de sua produção do que das exigências narrativas da matéria abordada, a que aquela composição serve de suporte e constituinte. Esse aparente lapso nos conduz a outras considerações, se lembrarmos que a expressão do poeta se fia numa conjunção dialética entre história e o significado simbólico que ela adquire, desdobrado na sua poesia. Como a forma do poema se faz também um dos elementos que ajudam a sedimentar o viés simbólico da história que João Cabral reclama, salta aos olhos que ele faça um uso próprio da forma, destacando quadras, octossílabos, sintaxe condensada e vocabulário comum que ressalta o nome de figuras históricas. Essa aparente tranquilidade com que o poeta concilia termos tão contraditórios pode ser lida, na verdade, como a mimetização do discurso histórico que apazigua um sem-número de contradições. Ao apresentar-se, moderadamente tenso, o poema de João Cabral chama a atenção através da forma para contradições que parecem resolvidas, embora com serenidade ele as mostre irresolutas, até mesmo sob o ponto de vista da forma. Nesse poema, tal conjunção não é processada com a mesma eficácia de outros casos mais conhecidos em que matéria e forma sob tensão se fundem para dar corpo à sua expressão. Não fosse pelos característicos octossílabos e pela toante das quadras, de tão comportado na superfície, o poema poderia ser associado até a outro autor, que não aquele João Cabral incontido, a pique de explodir. No entanto, tal arrefecimento da forma é que produz um poema estranho, a ser estranhado inclusive como peça de João Cabral. 
Mais do que refratária, deslocada ou circunstancial, a objetividade cabralina revelada no poema simula-se interessada num tipo bem específico de exploração da descrição histórica, como se estivesse imbuída da tarefa de celebrar mitologias, revelando-se precária já no seu intento ao se basear na história contra a qual o mito se insurge por princípio. Assentada a diferença entre o projeto e a realização no plano discursivo, não menos curioso é que a história e o mito, tomados como grandezas excludentes, se revelam como áreas conflitivas no interior daquela poesia, que não as sedimenta. A história e o homem que se deslindam a partir do poema "Abreu e Lima" se esfarelam mutuamente, inclusive porque se equilibram no poema através do sujeito que lhes dá voz e talvez só devido a este mecanismo é que ganhem unidade ali, porque se submetem à intervenção de um sujeito ordenador.

Assim, a história não se subordina à historiografia nos termos esperados, posto que tenha sido avariada pela exploração que o poeta lhe devotou. Tampouco podemos restringir aquela história a uma mitologia particular do poeta, porque aponta com pretensa exatidão para acontecimentos exteriores ao sujeito. O desconhecimento da história ultrajada não é suplantado efetivamente e se abre em precedente para mistificação. A expressão arredia daquele sujeito poético se redime noutros termos, quando concilia uma imagem à sua expectativa, ainda que estejam fraturadas na sua base, a imagem e a expressão do sujeito. $\mathrm{O}$ intento de unir poesia e história se realiza bem, porque houve um fracasso, que é transmitido no discurso histórico e também na realização poética de um sujeito bem circunstanciado. Só por isso se fortalecem ambos, a história e a poesia, ainda que o feito tenha sido precário nas duas dimensões em que o texto se encerra, seja histórica ou poética. Em ambos os casos, a precariedade do resultado é que chama a atenção, tanto como informação desencontrada quanto como realização formal inacabada, posto que se valha de um suporte histórico que é, já de si, avariado naquela composição. 


\section{Referências}

CARNEIRO, E. A insurreição praieira. Rio de Janeiro: Conquista, 1960. CHACON, V. O romântico de 1848: Abreu e Lima. In: CHACON, V. História das idéias socialistas no Brasil. Rio de Janeiro: Civilização Brasileira, 1965.

CHACON, V. Abreu e Lima: general de Bolívar. Rio de Janeiro: Paz e Terra 1983.

COSTA, F. A. P. da. Dicionário biográfico de pernambucanos célebres. Recife: Fundação de Cultura Cidade do Recife,1981.

PAGANO, S. O conde dos Arcos e a revolução de 1817. São Paulo: Nacional, 1938.

LIMA SOBRINHO, B. A revolução praieira. Recife: Imprensa Oficial, 1949.

MELLO, J. M. F. de. Autos do inquérito da Revolução Praieira. Brasília: Senado Federal, 1979.

MELO NETO, J. C. de. Poesia completa e prosa. Rio de Janeiro: Nova Aguilar, 2008.

NABUCO, J. A luta da Praia. In: NABUCO, J. Um estadista do império. Rio de Janeiro: Topbooks, 1997. V. 1, p. 93-120.

SCHWARCZ, L. M. Os institutos históricos e geográficos: "guardiães da história oficial”. In: SCHWARCZ, L. M. O espetáculo das raças: cientistas, instituições e questão racial no Brasil (1870-1930). São Paulo: Companhia das Letras, 1993. p. 99-140

SECCHIN, A. C. João Cabral: a poesia do menos e outros ensaios cabralinos. Rio de Janeiro: Topbooks, 1999.

SOUZA, R. A. de. O cônego e o general: uma controvérsia matricial sobre a idéia de literatura brasileira. In: SOUZA, R. A. de. Introdução à bistoriografia da literatura brasileira. Rio de Janeiro: Eduerj, 2007. p. 41-53. 
